\title{
Varying Use of Conceptual Metaphors across Levels of Expertise in Thermodynamics
}

\author{
Fredrik Jeppsson, Jesper Haglund and Tamer G. Amin
}

\section{Linköping University Post Print}

\section{Tweet}

N.B.: When citing this work, cite the original article.

This is an electronic version of an article published in:

Fredrik Jeppsson, Jesper Haglund and Tamer G. Amin, Varying Use of Conceptual Metaphors across Levels of Expertise in Thermodynamics, 2015, International Journal of Science Education, (37), 5-6, 780-805.

International Journal of Science Education is available online at informaworldTM:

http://dx.doi.org/10.1080/09500693.2015.1025247

Copyright: Taylor \& Francis (Routledge): SSH Titles

http://www.routledge.com/

Postprint available at: Linköping University Electronic Press

http://urn.kb.se/resolve?urn=urn:nbn:se:liu:diva-118248 


\title{
Varying Use of Conceptual Metaphors across Levels of Expertise
}

\section{in Thermodynamics ${ }^{1}$}

\author{
Fredrik Jeppsson $^{\mathrm{a}^{*}}$, Jesper Haglund ${ }^{\mathrm{b}}$ and Tamer G. Amin ${ }^{\mathrm{c}}$ \\ a Department of Social and Welfare Studies, Linköping University, 60174 \\ Norrköping, Sweden, +46-11-363181, fredrik.jeppsson@liu.se. \\ ${ }^{\mathrm{b}}$ Department of Physics and Astronomy, Uppsala University, Box 516, 75120 \\ Uppsala, Sweden, +46-18-4713544, jesper.haglund@physics.uu.se. \\ ${ }^{c}$ Science and Mathematics Education Center, Department of Education, \\ American University of Beirut, P.O. Box: 11-0236, Bliss Street, Beirut, \\ Lebanon, (961)1350-000 ext.3096, tamer.amin@aub.edu.lb \\ * Corresponding author.
}

Keywords: Conceptual metaphor; Thermodynamics; Problem-solving; Expertise

1 To appear in Special Issue: Conceptual metaphor and embodied cognition in science learning. International Journal of Science Education. 


\title{
Varying Use of Conceptual Metaphors across Levels of Expertise
}

\author{
in Thermodynamics
}

\begin{abstract}
Many studies have previously focused on how people with different levels of expertise solve physics problems. In early work, focus was on characterising differences between experts and novices and a key finding was the central role that propositionally expressed principles and laws play in expert, but not novice, problem solving. A more recent line of research has focused on characterizing continuity between experts and novices at the level of nonpropositional knowledge structures and processes such as image-schemas, imagistic simulation and analogical reasoning. This study contributes to an emerging literature addressing the coordination of both propositional and non-propositional knowledge structures and processes in the development of expertise. Specifically, in this paper we compare problem solving across two levels of expertise - undergraduate students of chemistry and $\mathrm{PhD}$ students in physical chemistry - identifying differences in how conceptual metaphors are used (or not) to coordinate propositional and non-propositional knowledge structures in the context of solving problems on entropy. It is hypothesized that the acquisition of expertise involves learning to coordinate the use of conceptual metaphors to interpret propositional (linguistic and mathematical) knowledge and apply it to specific problem situations. Moreover, we suggest that with increasing expertise, the use of conceptual metaphors involves a greater degree of subjective engagement with physical entities and processes. Implications for research on learning and instructional practice are discussed.
\end{abstract}




\section{Introduction}

The study of expertise in science has been a topic of investigation for some time. Various perspectives can be found in the literature. Early work on expertise focused on the differences between novices and experts, identifying the important role of abstract principles in the latter, absent in the former (Chi, 2006a, 2006b; Chi, Feltovich, \& Glaser, 1981; Chi, Glaser, \& Rees, 1982). Another line of work has focused on continuity between novices and experts by focusing on non-propositional knowledge structures such as imagery, image-schemas (abstractions from sensorimotor schemas) and mental models (Clement, 2009; diSessa, 1993; Hammer, 2000; Smith, diSessa, \& Roschelle, 1993). This latter approach can be seen as reflecting a kind of "embodiment turn" in research on scientific expertise and science learning. More recently, it has been increasingly acknowledged that scientific expertise involves the coordination of abstract knowledge, formulated propositionally, and nonpropositional knowledge structures and processes (e.g. Amin, 2009; Amin, Smith, \& Wiser, 2014; Cheng \& Brown, 2010; Jeppsson, Haglund, Amin, \& Strömdahl, 2013; Sherin, 2001, 2006). The study reported in this paper contributes to this recent effort aimed at understanding the difference between novices and experts in terms of both propositionally represented knowledge and non-formal knowledge structures and processes. We use the term propositional to refer to language-like representations (such as natural language and mathematical representations) which bear no resemblance to what they represent and express a belief that can be judged true or false. We use the term non-propositional to refer to analogical representations that preserve structural features of what they represent, such as images, image-schematic abstractions from sensorimotor experience and mental models. In a previous study (Jeppsson et al., 2013), we investigated the role that systematic metaphorical mappings (conceptual metaphors), implicit in language, play in advanced problem-solving in thermodynamics. One of the findings in that study was that the advanced scientific problem solving of $\mathrm{PhD}$ students in physical chemistry involved the coordination of multiple imageschemas with each other and with propositional knowledge expressed through language and mathematics. The present study extends this previous research by examining how this coordination differs in $\mathrm{PhD}$ students and undergraduates. The purpose is to identify whether the acquisition of expertise in scientific problem solving involves changes in how nonpropositional and propositional knowledge structures are coordinated, with a particular emphasis on the changing roles of conceptual metaphors. 
In the rest of this introduction, we briefly review the literature on scientific expertise, reviewing first the literature focusing on the differences between novices and experts, followed by literature focusing on the continuity between them at the level of nonpropositional knowledge structures and processes, and finally, turn to recent literature beginning to examine the coordination of propositional and non-propositional knowledge.

For a number of decades, there has been an interest in how the problem-solving strategies of experts and novices differ, with many studies focusing on physics problem solving in particular (e.g. Chi, 2006a; Chi et al., 1981; Chi et al., 1982). While many cognitive scientists have been motivated primarily by interest in foundational understanding of the nature of expertise, studying scientific reasoning by experts has been seen by some as a way to understand how we can help others to become more skilled and knowledgeable, that is, this research has been conducted from an educational perspective (Chi, 2006b; Clement, 2009). Based on Hoffman's (1998) scale of proficiency, Chi (2006b) argues for a continuum of levels from the novice to the master, a person regarded by other experts as being the expert. Intermediate levels, paralleling the historical hierarchy of workmanship, include the apprentice, a student engaged in instruction beyond the introductory level, and the journeyman, who has developed a higher level of competence and independence. Early work by Chi and colleagues (e.g. Chi et al., 1981; Chi et al., 1982) found that one qualitative difference between novices and experts lies in how they categorise and represent physics problems. Chi et al. (1981) found that novices categorised problems in terms of concrete "surface similarities", such as the shared physical objects involved in the problem situation (e.g. blocks on an inclined plane), whereas experts categorised problems in terms of more general "physical principles" (e.g. the law of conservation of energy). Such differences in categorisation may be due to the experts' representation of the problems in terms of idealised objects and the physics concepts involved, such as force, while novices rely on representation of the literal objects and their spatial relationships.

In contrast to Chi et al.'s (1981) focus on differences between novices and experts in the use of propositionally expressed laws and principles, a number of researchers have emphasized the important role that non-propositional knowledge structures and modes of reasoning play in scientific expertise and the continuity that this implies with the cognitive resources available to novices. diSessa (1993) provided an extended account of the role of abstractions from sensorimotor experiences, what he called "p-prims", in scientific understanding and reasoning. In that account, scientific expertise involved the coordination of multiple p-prims. Given that p-prims are knowledge structures formed early in life through 
interactions with the physical world, their use by experts reflect a source of continuity between novices and experts. On this view, learning involves a reorganization of knowledge structures already possessed by the novice. In addition, Clement (2009) has shown that experts make use of non-propositional resources in their approach to solving more challenging physics problems. When he analysed transcripts of scientists' thinking aloud while they solved problems, Clement found that abstract scientific understanding and reasoning are grounded in more concrete, bodily-based knowledge structures and nonpropositional modes of reasoning, including analogical reasoning, imagistic simulation and application of physical intuition. These types of knowledge structures and modes of reasoning are assumed to be resources available to the learner and contribute to creative leaps in understanding, and so Clement suggested that these should, therefore, be given more attention in science education. In a similar vein, within cognitive science research, but recognised as applicable to science education (Stolpe \& Björklund, 2011), Dreyfus, Dreyfus and Athanasiou (1986) describe how a person may advance from a novice to expert passing through five levels. They claim that engagement of intuitive reasoning is the crucial feature that distinguishes the two highest levels - "proficiency" and "expertise" - from the preceding "novice", "advanced beginner" and "competent person" levels, which rely on the adherence to explicit propositional rules.

This interest in the role of non-propositional structures and modes of reasoning in scientific expertise, parallel a more general "embodiment turn" in cognitive science. Cognitive science has traditionally relied on the analogy of the mind to a computer, and that our cognition can be modelled fruitfully in terms of propositional representations made up of arbitrary symbols and processing that involves the manipulation of those symbols modelled as formal logic (e.g. Larkin, McDermott, Simon, \& Simon, 1980). Embodied cognition has evolved as a diverse movement, which nonetheless unites around the critique of this traditional approach to cognitive science (e.g. Barsalou, 2008; Clark, 2008; Dreyfus et al., 1986; Lakoff \& Johnson, 1980, 1999; Varela, Thompson, \& Rosch, 1991). One central idea of embodied cognition is that even the representation of apparently abstract conceptual knowledge and abstract reasoning relies heavily on our concrete experiences of perceptual and motor interaction with our surroundings, as well as our capacity for mental, imagistic simulation.

Contributing to the embodiment turn in cognitive science, Lakoff and Johnson (1980, 1999) have put forward the construct of conceptual metaphor, arguing that we typically come to understand abstract concepts by implicit reference to more concrete, visceral experiences. 
Such concrete experiences, in turn, are organised by use of image schemata (Johnson, 1987), preconceptual abstractions from sensorimotor experiences. An example is the CONTAINER image schema, by which we conceive of objects being located inside or outside of a bounded region in space, or going into or out of it. Further, Lakoff and Johnson (1999) describe two different, but related ways in which we organise our understanding of abstract states and changes of state: the Location Event-Structure metaphor and the Object Event-Structure metaphor. In the Location Event-Structure metaphor, states are construed as if they were locations in space (e.g. "I'm in a depression"), changes are construed as movement between locations (e.g. "I got out of my depression") and caused changes as forced movement (e.g. "His joy of life pulled me out of my depression"). With a subtle figure-ground reversal, in the Object Event-Structure metaphor, states are construed as if they were objects/possessions (e.g. "I have a cold") changes of state are construed as the transfer of possessions (e.g. "I got her cold") and caused changes of state are construed as forced transfer of possessions (e.g. "She gave me her cold"). Lakoff and Núñez (2000) argue that even mathematics - one of the most abstract domains of human thought - is embodied, grounded in image-schematic abstractions from sensorimotor experiences.

An embodied cognition perspective has received increasing attention in science education. Andersson (1986) argued that pupils apply the notion of an experiential gestalt of causation (Lakoff \& Johnson, 1980), a general structure of causation where an agent causes some kind of change in an object, when thinking about a range of scientific topics including phase changes, electric circuits and vision. Adopting an embodied cognition perspective, Reiner (2000) analysed students' collaborative thought experiments regarding the optimal path in a downhill bike race and found that they used a combination of BALANCE and SYMMETRY image schemata. Consequently, Reiner and Gilbert (2000) suggest that bodily knowledge, expressed as image schemata, help us evoke non-propositional images of forces, through which we can make predictions of future events.

Another line of thought that fits within the embodied cognition tradition, is the idea that empathising with, or even experiencing identification with aspects of natural phenomena, through imaginative mental simulation of a physical situation, contributes to understanding science (Ochs, Gonzales, \& Jacoby, 1996; Root-Bernstein, 2002). Root-Bernstein (2002) points out that many prominent scientists have testified to such immediate rapport with natural phenomena. For instance, virologist Jonas Salk (1983, p. 7) reported that: 'I would picture myself as a virus or a cancer cell, for example, and try to sense what it was like to be either and how the immune system would respond.' Similarly, Einstein (1954, p. 226) 
claimed: 'There is no logical path to these [universal elementary] laws; only intuition, resting on sympathetic understanding of experience, can reach them.' In their analysis of the discourse in a solid state physics group, Ochs, Gonzales and Jacoby (1996) point out that in addition to detached physics-centred language typical of scientific journals, in oral discourse, the physicists also expressed subjective involvement with the phenomena. They not only conceived themselves as experiencing or manipulating the phenomena, but also identified with the phenomena and representations of them in graphs that they drew, as expressed in the title quote: 'When I come down I'm in the domain state.' Consequently, Root-Bernstein (2002, p. 68) promotes the ability to empathise with phenomena as 'an important tool in the mental arsenal' for science students to adopt.

Science educators who have taken an interest in the role of identification with natural phenomena in science learning include Wilensky and Reisman (2006), who encouraged students to model the behaviour and interaction of individual organisms as a way to understand ecosystems. Further, Scherr and colleagues have developed the Energy Theater, in which learners take on the embodied role of energy units, which undergo transfer and transformation as they enact physical scenarios (Scherr et al., 2013) . All of these applications of an embodied cognition perspective on scientific expertise and science learning emphasise the continuity between the novice and expert at the level of non-propositional knowledge structures and reasoning processes.

A number of researchers have begun to investigate scientific expertise as the coordinated use of propositional and non-propositional knowledge structures and processes (Amin, 2009; Amin, Jeppsson, Haglund, \& Strömdahl, 2012; Cheng \& Brown, 2010; diSessa \& Sherin, 1998; Georgiou, 2014; Jeppsson et al., 2013; Sherin, 2001; Singh, 2002). diSessa \& Sherin (1998) extended diSessa's earlier work on p-prims as a constituent of expert scientific understanding and reasoning, by proposing the construct of a coordination class. On their account, a coordination class is a knowledge system (seen as an alternative construct to the notion of "concept") made up of heterogeneous types of knowledge elements including non-propositional p-prims and mental models as well as propositionally formulated beliefs, scientific laws and principles. Developing expert understanding of a scientific concept is to strategically assemble and apply these knowledge elements in such a way as to enable consistent reasoning across a range of physical situations. In addition, in an effort to bridge between accounts of qualitative and quantitative reasoning in scientific expertise, Sherin (2001) has identified what he calls symbolic forms, knowledge structures that enable the meaningful interpretation of elements of physics equations. Symbolic forms are composed of 
two components: a "symbol template" which is a generic pattern of symbols in an equation; and an associated intuitive conceptual schema, which is similar to, and in some cases is a pprim. The conceptual schema interprets patterns of symbols in equations. For example, the generic pattern of symbols, or "symbol template," consisting of two terms separated by an equal sign $(\square=\square)$, can be interpreted in terms of the conceptual schema of two balancing influences (which is the p-prim balancing). According to Sherin, an expert problem-solver will make use of many symbolic forms which give meaning to aspects of equations and help in connecting between qualitative understanding of a physical situation and its mathematical representation.

Other researchers have also investigated the connection between propositional and non-propositional structures and processes in scientific expertise. Focusing on problemsolving strategies where intuition fails, Singh (2002) investigated 20 physics professors' problem-solving approaches to an introductory numerical physics task, designed to be of a novel structure and, therefore, difficult to target by gut intuition only. Singh found that in many cases the professors started their problem solving by searching for conservation principles, but also different kinds of visualisations and analogies to map the unfamiliar problem to a more familiar domain. In other words, they made use of a combination of principle-based reasoning (Chi et al., 1981) and concrete embodied experiences (Clement, 2009) in their problem-solving approach. This coordination has also been studied in the early stages of the acquisition of scientific expertise. For example, in their investigation of thirdand sixth-grade students' explanations of magnetic phenomena, Cheng and Brown (2010) found that the most advanced and robust reasoning relied on a combination of intuitive knowledge and more formal (what they called "verbal-symbolic") knowledge. Similarly, Georgiou (2014) analysed undergraduate students' work on context-rich thermodynamics problems, from the perspective of 'semantic gravity', the degree to which the meaning of language in a particular instance is dependent on its context. She focused on one problem, where the students were asked to explain the mechanism for why frost may form on the outside of a container of compressed gas when its valve is left open for a while. She found that successful, internally coherent responses relied on coordination of abstract physics principles with more context-dependent features of the problems. Poetically, she names failure through over-reliance on abstract principles, and thereby neglect of the particulars of the studied phenomenon, 'the Icarus effect', metaphorical disconnection from earthly matters. From this perspective, developing expertise in physics entails fathoming a broader range of semantic gravity, connecting general laws to particular circumstances. 
Some researchers have begun to characterise the pervasive conceptual metaphors that are implicit in the language of science and have begun to explore how they are implicated in expertise and its acquisition. Brookes and Etkina $(2007,2009)$ showed how physicists make frequent use of conceptual metaphors in areas such as quantum physics and Newtonian mechanics. These conceptual metaphors are encoded in the language of these domains. Brookes and Etkina argue that exposure to this language sometimes causes students to make erroneous (concrete) ontological categorisations of scientific concepts (Slotta, Chi, \& Joram, 1995) because of overly literal interpretations of metaphorical expressions (see also Brookes \& Etkina, this issue).

In previous work, we have identified extensive use of conceptual metaphors to construe abstract physical quantities in thermodynamics: energy in the The Feynman Lectures on Physics (Amin, 2009), and entropy and the second law of thermodynamics in university textbooks (Amin et al., 2012) and in $\mathrm{PhD}$ student problem-solving dialogues (Jeppsson et al., 2013). We have suggested that conceptual metaphor may be added to the list of productive intuitive resources that contribute to science learning. More specifically, we found that when solving problems on entropy, $\mathrm{PhD}$ students coordinated multiple conceptual metaphors together, and in conjunction with, the use of symbolic forms, which supported the alignment of qualitative and quantitative reasoning (Jeppsson et al., 2013). Thus, that previous study identified an example of the use of conceptual metaphors in the complex coordination between non-propositional and propositional knowledge elements in the context of advanced scientific problem solving. However, the original purpose of that study was broader; it had the more general goal of characterising the roles of conceptual metaphors in scientific problem solving. The present study returns to the think aloud protocols of the two $\mathrm{PhD}$ students of that previous study and reanalyses that data with a focus on the role of conceptual metaphor specifically in the coordination of propositional and non-propositional knowledge structures. Moreover, it examines undergraduate students' attempts to solve the same problems tackled by the $\mathrm{PhD}$ students, so as to examine whether the acquisition of expertise in scientific problem solving involves changes in how conceptual metaphors are used in scientific problem solving, specifically with regard to how non-propositional and propositional knowledge structures are coordinated. In sum, the research question we attempt to answer is: How does the use of conceptual metaphor differ in scientific problem solving at different levels of expertise, specifically with regard to how non-propositional and propositional knowledge structures are coordinated? We use the present qualitative study of the reasoning of two $\mathrm{PhD}$ students and two undergraduates to generate data-driven 
hypotheses about differences in the use of conceptual metaphors at different levels of expertise. Further research is needed to further validate the hypotheses generated and to extend them to a wider range of problem-solving contexts.

\section{Method}

In this study, two pairs of students - a pair of $\mathrm{PhD}$ students in physical chemistry and a pair of undergraduate chemistry students - were presented with three problems, each requiring an understanding and application of the concept of entropy. Each pair was asked to work together while thinking aloud to solve the problems. Verbatim transcripts of their problemsolving sessions were prepared and analysed for what they might reveal about the varying use of conceptual metaphor in problem solving, with specific focus on the coordination of propositional and non-propositional knowledge structures. In this section, we provide information about the participants in the study, the problems used, and the methods of data collection and analysis.

\section{Participants}

Four participants took part in this study: two Swedish $\mathrm{PhD}$ students specialising in physical chemistry and two Swedish undergraduate chemistry students. Along Chi's (2006b) novicemaster continuum, the $\mathrm{PhD}$ students may be characterised as journeymen, while the undergraduates are apprentices. The two $\mathrm{PhD}$ students (henceforth, $\mathrm{D} 1$ and $\mathrm{D} 2$ ) were well acquainted with thermodynamics at the postgraduate level. At the time of the study, both of them had approached the end of their doctoral studies and had taken graduate courses on statistical thermodynamics and physical chemistry. D1 focused his research on the study of the interaction energies between surfaces in solvents, while D2 studied statistical physics of nanoclusters. The two undergraduate students (S1 and S2) were halfway through the undergraduate chemistry program and had taken thermodynamics and statistical mechanics within a course on physical chemistry.

\section{Problems}


The participants were presented with three thermodynamics problems, which required an understanding and application of the concept of entropy, two of which - problem 1 and 3 are in focus in the current study of coordination between formal and non-formal knowledge resources. We summarise these problems here, while more detailed descriptions of the problems and possible solutions can be found in Jeppsson et al. (2013). In Problem 1, the participants were asked to account for the mechanism that drives the process of freezing water in a beaker that is placed in a freezer. A scientifically appropriate response to this question would recognize that as the water freezes, there is heat transfer from the water to the surroundings. During this process, the entropy of the surroundings increases more than the entropy decrease of the water; this net increase in entropy can be seen as what drives the process forward. Problem 3, in turn, involved establishing the entropy change of an ideal gas undergoing reversible, adiabatic expansion. A scientifically appropriate response would recognize that the entropy remains unchanged, since no heat is exchanged with the surroundings and $S=Q / T=0 \mathrm{~J} / \mathrm{K}$, due to the reversibility assumption.

\section{Data Collection and Analysis}

The student pairs spent approximately one hour discussing solutions to the three problems, in which the $\mathrm{PhD}$ students made 523 dialogue turns and the undergraduates made 238 , followed by a joint debriefing session of about 20 minutes. These sessions were video recorded. Verbatim transcripts were later prepared for subsequent analysis. The transcripts were entered into the MAXQDA software that supported the qualitative analysis of the problem solving sessions. The transcripts where analysed in four phases as follows. The first phase of the analysis involved segmenting the problem solving protocol for each problem into distinct reasoning episodes and interesting episodes were identified in which the pair made some progress towards their preferred solution. The second phase involved the identification of conceptual metaphors used in the selected episodes. These episodes were read and re-read repeatedly and candidate sentences that seemed to have metaphorical units were intuitively selected and later brought up in a group discussion among the authors on whether they should be regarded as metaphorical phrases or not. As a way to increase the reliability of metaphor identification, a simplified version of the Metaphor Identification Procedure (MIP) developed by the Pragglejaz Group (2007) was applied to the candidate metaphorical sentences. First, the candidate metaphorical lexical unit(s) in the sentence is(are) identified. Next the contextual meaning of the whole sentence is glossed and the meaning of the lexical unit(s) in 
context is described. The next step is to decide whether it has a more basic, more concrete meaning in another context. If there is, the researcher has to decide whether the basic meaning contrasts with the contextual meaning of the lexical unit. If it does, the usage is considered to be metaphorical. After applying the MIP in each selected episode in this way, instances of use of conceptual metaphors were then identified by generalizing across different metaphorical units and drawing from the literature on conceptual metaphor. Here is an example of the our application of the MIP in our analysis.

Example: '...delta $\mathrm{S}$ as a function of $[\mathrm{T}]$ for a certain delta $\mathrm{Q}$, one gets something like this ...'

Candidate metaphorical lexical units: "one gets"

Contextual meaning:

(1) Of whole sentence: When applying the formula $\mathrm{d} S=\mathrm{d} Q / T$ and you have a certain amount of heat exchanged at some temperature the resulting change in entropy that can be calculated is...

(2) Of candidate metaphorical lexical units "one gets": The result of the calculation is.

In the example above, "one gets" means something along the lines of "the result of the calculation is." However, "one gets" has a more literal meaning in terms of reception of a tangible object, transfer of possession. By seeing multiple metaphorical expressions dealing with the metaphorical transfer of possession into or out of a function and based on knowledge of conceptual metaphors identified in the literature, we interpret, "one gets" as reflecting the Function Is A Machine conceptual metaphor, where a function is construed as a machine that takes objects as inputs and giving objects as outputs. Therefore, "one gets" is treated as a metaphorical unit where the abstract output from a function is construed as a concrete object you can physically manipulate in different ways. Note that "one gets something like this" comes across as perfectly conventional in the context of calculating functions; its metaphorical origin is identified only through careful analysis.

In the third phase of the analysis, the role that these conceptual metaphors played in the reasoning of the episode was described. Moreover, this role was described in relation to the use of other knowledge elements in the problem solution. For the purposes of this particular study, we were interested in distinguishing the use of propositional and nonpropositional knowledge structures in the reasoning. We limited our attempts to identify nonpropositional knowledge structures to two types of structures: image-schemas that can be 
inferred as the source domains of conceptual metaphors reflected in metaphorical expressions uttered by the participants; and the conceptual schemas associated with symbolic forms inferred in the analysis of the problem solving protocol. Once this analysis was carried out for the transcript of each pair, a fourth phase of the analysis involved making comparisons across pairs. Of interest was how the use of conceptual metaphors differed in the problem solutions of the two pairs, with particular focus on the coordination (or absence thereof) of propositional and non-propositional knowledge structures.

We should note that in our previous analysis of the PhD students' problem-solving protocol, we found frequent metaphorical use of pronouns ('I', 'we', 'you', or 'one'). In this study as well, the application of the MIP revealed the metaphorical use of pronouns. Prompted by prior research by others suggesting that expertise in science involves a high degree of conceptual engagement by scientists with their objects of investigation (e.g. Ochs et al. 1996 reviewed above) the level of engagement was compared across levels of expertise. To do this conceptual metaphors reflecting three distinct levels of increasing engagement with the phenomenon were identified: A Problem Solver Is An Owner/Observer Of A System, A Problem Solver Is A Manipulator Of A System, and A Problem Solver Is A System. The frequency of use of each of these conceptual metaphors in each transcript was determined and profiles of use by undergraduates and $\mathrm{PhD}$ students were compared.

\section{Results}

In this section, we present the results of the analyses conducted on the $\mathrm{PhD}$ students' and the undergraduate students' problem solving discussions separately. In presenting the results of our analyses of each pair's problem solving, we: provide an illustrative excerpt from the transcript of the pair's problem solving discussion; present the conceptual metaphors (CMs) used in the problem solution and then explain the extent and nature of the coordination between propositional and non-propositional knowledge structures. At the end of this section, we then turn to a comparison of the roles of conceptual metaphors in both pairs' problemsolving approaches, with an emphasis on how they differ with respect to the coordination of propositional and non-propositional knowledge structures and the degree of engagement with the physical systems being considered. 
Problem 1. In the first problem, the students were asked what drives the freezing of water in a beaker at a temperature of $0^{\circ} \mathrm{C}$ when it is moved to a freezer at $-10^{\circ} \mathrm{C}$. The following excerpt presents the central episode in their attempt to solve this problem:

D2: Well, in this case... er, I guess it's simply that... if I take heat from this beaker with water... and move over to the room... in principle, then... the partition function in... for the room will increase... more than what I lose in the beaker, then...

D1: Uhum...

D2: Now, let's see... it's...

D1: ...the entropy, you mean...?

D2: Yes, in principle, that is the entropy... so.../../ delta $S$ as a function of $[T]$ for a certain delta $Q$, one gets something like this . . . /../ so, maybe . . the lower the temperature, the bigger the entropy gain you get if you move some heat into this system . . . so, that means for our heat bath system here... that if you move a small amount of heat from the water beaker out to the room . . then, the entropy in the room will increase more than the entropy has decreased in the water beaker . . due to the reason that it is colder in the room ...

The words marked in bold in the excerpt above indicate lexical items that reflect the use of implicit conceptual metaphors. In 'If I take heat from ... and move over to ...' D2 talks about heat as a substance/possession, which he imagines moving from the considered system to its surroundings. This reflects the use of two CMs, Change of State is Transfer of a Possession (applied to heat) and the metaphorical use of the pronoun "I", which reflects the CM A Problem Solver is a Manipulator of a System. The same two metaphors are also used (this time using the pronoun "you") in "If you move some heat into this system" and "if you move a small amount of heat from the water beaker out to the room". Moreover, the CM Change of State is Transfer of a Possession is used again; this time applied to entropy change in "more than what I lose in the beaker" and "the bigger the entropy gain you get ...." In addition, the "I" in "more than what I lose" reflects the CM A Problem Solver Is An Owner Of A System. The phrase "the bigger the entropy gain you get" also reflects two other implicit CMs: The use of "get" reflects the A Function Is A Machine CM and the use of the pronoun "you" reflects the CM The Problem Solver Is Manipulator of a Machine.

Our previous analysis of this reasoning episode, reported in Jeppsson et al. (2013), emphasised the coherence of the source domains in the coordination of these CMs. We noted 
that the source domains used to construe the qualitative and quantitative aspects of the problem, respectively, fit into coherent images, with alignment between the images - i.e. the coherent image of a manipulator of the system moving possessions from one location to another construing the changes of state of parts of the system and surroundings, and the manipulator of the machine providing input and receiving output. We suggested that this coordinated use of CMs in order to align qualitative and quantitative reasoning was a central contribution of CMs to problem solving. We also noted the coordination of these CMs with the use of the "prop-" symbolic form (Sherin, 2001) to interpret the formula $d S=d Q / T$ with a focus on temperature as the denominator. This allowed the $\mathrm{PhD}$ students to compare the entropy change in the beaker and its surroundings, and conclude that the entropy increase in the (lower temperature) surroundings is greater than the entropy change in the (higher temperature) beaker.

What we would like to add here is an explicit consideration of the representational modes of the knowledge structures - propositional and non-propositional - being employed in this reasoning. We must note at the outset that this whole excerpt is, of course, realised in language. Careful analysis could be conducted of the gestures the $\mathrm{PhD}$ students used (as carried out by Dreyfus et al., this issue) and/or the diagrams they drew (Clement, 2009). However, our interest in conceptual metaphor has led us to focus on verbal realisations of the reasoning, that is, propositional reasoning, formulated using the lexical and syntactic resources of natural language. However, our analysis of elements of the language as reflecting CMs allows us to identify underlying image-schematic source domains - namely, substances/possessions, transfer of possessions from one location to another, machines, input to and output from machines.

In our analysis, we also ask: what are the central propositional representations that play a role in the reasoning? We note first D2's remark 'in principle, then... the partition function in... for the room will increase... more than what I lose in the beaker' as central to the reasoning in this excerpt. In fact we can see the rest as unpacking the meaning underlying this statement. The partition function is introduced in statistical mechanics, representing the way the energy of a system is distributed across discrete energy levels. Here, at a macroscopic level, the partition function may be seen to roughly represent the entropy. Although D2's expression 'in principle' is perhaps a brief discourse marker, it signifies that in his view his solution must adhere to a foundational principle, the second law of thermodynamics, according to which the total entropy of the system and its surroundings cannot decrease. This is a strict adherence to a propositionally expressed law and illustrates 
principle-based reasoning, noted by Chi et al. (1981) as an important characteristic of expertise. Next, the mathematical formula expressing the relationship between change in entropy, exchange of heat and temperature, $d S=d Q / T$, is another propositional representation that plays a central role in the reasoning. In applying this formula to the water in the beaker and the air in the freezer surrounding the beaker and comparing the values, the second law of thermodynamics frames the particular situation in this problem.

Based on this analysis of the resources made use of in the solution to this problem, we hypothesize the following joint contributions of both the propositional and image-schematic (non-propositional) knowledge structures. The propositionally expressed second law and the mathematical formula $d S=d Q / T$ might be seen as constraints on the reasoning carried out. The problem solvers know them and know their status as principles that must be obeyed. The image-schematic structures, reflected in metaphorical verbal expressions, allow for the use of more concrete, cognitive resources to interpret these abstract propositions. Moreover, they allow for the meanings of the two propositions to be coordinated easily. Interpreting entropy change as possession transfer in both cases allows for a common interpretation of the concept of entropy in both. Moreover, as we have noted above, interpreting heat as a possession that is transferred at both the qualitative and quantitative levels also allows for coordination between the interpretation of the physical situation being considered, and the mathematical formula being used to draw conclusions about it.

We must acknowledge that this analysis can only be seen as a hypothesized interpretation of descriptive data. For example, the counter argument that the conceptual metaphors reflected in the transcript are relatively superficial linguistic phenomena not contributing the reasoning must be entertained. We would argue that the consistent and coherent use of source domains of possession and transfer of possession suggest that what we are revealing is a conceptual phenomenon, but other methods (e.g. psycholinguistic techniques and gesture analysis) would be required to adjudicate this. Moreover, the plausibility of treating the propositionally expressed second law of thermodynamics and the mathematical formula $d S=d Q / T$ as "constraints" on the non-propositional knowledge elements used warrants discussion. Hypothesizing this constraint role amounts to making a causal claim - namely, that the propositional representation influences what nonpropositional knowledge elements are triggered. Again, a descriptive study cannot provide unequivocal evidence for this claim. However, suggestive discursive evidence can be provided: the use (twice) of the discourse marker "in principle;" the appeal to the proposition early in the reasoning episode; and the central role of the CM A Function Is A Machine (with 
respect to which the other CMs cohere as explained above), which interprets that mathematical formula used to solve the problem.

Problem 3. Problem 3 required determining the entropy change of an ideal gas undergoing reversible, adiabatic expansion. As mentioned, the expected answer is that the entropy remains unchanged, since no heat is exchanged with the surroundings and $S=Q / T=0 \mathrm{~J} / \mathrm{K}$ in the reversible process. The following excerpt from the PhD students' problem solving session is the central episode in their thinking through a solution to Problem 3:

D2: So, the definition of a reversible process actually is that the entropy does not change...

D1: Well, right... [draws a PV diagram] It is that... it's a question of that one walks along the same

line... if one increases the volume... and then, when one decreases the volume, then...

D2: ... you can get back to the same state...

D1: Yes, right.

D2: Then you can't have had any entropy losses... because you can never decrease the entropy in an isolated system...

D1: No.

D2: Because if you are going to be able to get back to the same point, then you can't increase it either, right, because then you won't get back...

D1: It's always strange to think that [the entropy] is the same . . but, well . . I guess that's what it is . . . it [the problem-solving approach] goes straight to the entropy . . . that it would be presupposed that one gets more locations to be in ...

Again, we begin by pointing out the CMs used in this episode. First, there is consistent and joint use of the CMs A Problem Solver Is A System, States (Of A System) Are Locations and Change Of State Is Movement, reflected in the metaphorical use of the pronouns "one" and "you" in the phrases 'one walks along the same line' and 'you won't get back', and 'one gets more locations to be in'. As we noted in Jeppsson et al. (2013), this use of pronouns reflects integration of three things: the system, the points on the graph and the problem solver. A different metaphorical use of pronouns can be found in 'you can never decrease the entropy in an isolated system', which reflects the CM A Problem Solver Is A Manipulator Of A System. Moreover, we find the CM Change Of State Is Transfer Of A Possession (applied to entropy) in 'entropy losses'.

Next we consider the role of propositional and non-propositional knowledge structures in this reasoning episode. We note first the opening statement made by D2: "the definition of a reversible process actually is that the entropy does not change." Again, this 
reflects the use of a propositional formulation of a foundational characteristic (a "definition" as D2 puts it) of reversible processes that the total entropy of a system and its surroundings remains unchanged as a constraint on the reasoning that follows (Chi et al., 1981). The use of the CMs and the image-schematic source domain of which they are constituted play a different role in this episode than we saw in the excerpt for Problem 1 above. In that case, multiple CMs were used to align the construal of aspects of the qualitative and quantitative reasoning, where the latter was central to the solution of the problem. In the case of the excerpt under consideration here, the complex cognitive task of applying the principle of no entropy change in the reversible system to the relationship between the pressure and volume of the gas and the graphical representation of that relationship was supported through the coordination of conceptual metaphors listed above. Specifically, the constraint implied by the principle seems to be reinterpreted for the purposes of reasoning about this particular problem situation by conceiving of an individual walking along a constrained path with that image interpreting the continuous curve on the pressure-volume graph.

Even though the PhD students had produced an accurate solution to the given problem through a combination of attention to the particulars of the situation and principle-based reasoning, D1 still felt that their answer went against his intuition, as reflected in the last turn of the excerpt: 'It's always strange...' This discomfort probably stems from the salience of the increase in microstates due to increased volume, in comparison to the negative contribution from the decreased energy to be distributed across the particles. This interpretation is supported by the finding that it is common for students to ascribe an entropy increase to a system undergoing adiabatic, reversible expansion, due to the volume increase, and ignore the reduction of the internal energy of the system (Brosseau \& Viard, 1992; Haglund \& Jeppsson, 2014). The difficulty of carrying out conventional, scientifically sanctioned metaphorical mappings of intuitive, image-schematic structures to abstract scientific concepts has already been noted in the literature (Brookes \& Etkina, 2007). Nevertheless, of particular interest here is that D1 seems to accept D2's principle-based approach that 'goes straight to the entropy' as a constraint, and thus suppresses his intuition (i.e. the more obvious metaphorical mapping) in favour of the propositionally formulated principle.

However, again, it is important to be cautious about such interpretations from descriptive data. Indeed, a potential counter argument to the role of propositional constraints is suggested by an exchange in the debriefing session that followed, where the two students reflected upon the problem-solving process: 
D2: I tested both... like, microscopic, macroscopic... do a bit of calculations... to see what one gets... so I guess... one uses the method that seems most straightforward.../... ...to get to an answer.

D1: One suspects an answer... and then one works towards it. [laughter]

D2: Yes, one often has a hunch about... maybe from a macroscopic perspective, of what the answer should be... /.../ And then, one can, from a microscopic perspective... work forward and see if one... if one gets it [the answer]... if one doesn't get it, one had probably done something wrong somewhere! [laughter]

Here, the $\mathrm{PhD}$ students conceptualise the problem-solving process by recourse to a metaphor of physical travelling, the CM Problem Solving Is Walking Along A Path. This is indicated by expressions, such as 'straightforward', 'get to an answer', 'one works towards it' and 'work forward'. This metaphor referring to travelling is interlaced with another common construal, A Function Is A Machine, as expressed in 'to see what one gets', where the answer is represented as an object obtained from the process rather than a location at which one arrives at the end of the process. Framed within the issue of the difference between experts' and novices' problem solving, the $\mathrm{PhD}$ students' expression of suspicion, or having a hunch, points to the intuitive, qualitative character of assessing what might be a reasonable answer followed by deciding on a suitable, quantitative approach to confirm it (Dreyfus et al., 1986). However, D2 refers to 'do a bit of calculations' at an early stage of the problem solving process. So the process of coming up with a hunch may, as we suggested in our interpretation of the $\mathrm{PhD}$ students' work with problem 3, be constrained by identification of relevant physics principles (Chi et al., 1981). What seems quite clear, however, is that successful problem solving involves a coordination of formal and non-formal knowledge resources.

\section{Analysis of the Undergraduate Students' Problem Solving}

We have now seen how the $\mathrm{PhD}$ students successfully coordinated different nonpropositional, embodied resources with each other and in conjunction with propositionally formulated physical principles. We turn now to investigating how the pair of undergraduate students, apprentices in Chi's (2006b) scheme, approached these problems and what roles propositional and non-propositional knowledge structures play. 
Problem 1. The undergraduate students started with Problem 1, where they were asked to explain what drives forward the process of freezing water placed in a freezer. The following excerpts reflect the heart of their attempts to reason through this problem:

S2: Well, what drives it all has to be, in some way, that the entropy increases, as always.../.../

$\mathrm{S} 1$ : The standard solution... in what way the entropy increases is then... it's because... temperature equalisation is always... there is without exception always an entropy increase [they giggle].

After some time, when the students wrestle with focusing either on the process of freezing of the water or the exchange of heat with the surrounding air, they turn to modelling at the microscopic level:

S1: Well, the energy that gets released when... the molecules solidify into crystals... is used to heat up a 10 degree colder environment.

S2: Yes. And what is really the thing with freezing, anyway? Or why does it happen at a certain temperature...? Well, I don't know...

We note at the outset the rather limited use of conceptual metaphors (with metaphorically used words indicated in bold). The use of 'drives' (which is repeated from the initial formulation of the problem presented to them) reflects the CM Change Of State Is Forced Movement. 'The energy that gets released ...' reflects the CM Change Of State Is Transfer Of Possession, with 'used' elaborating the construal of the possession/energy as a resource. So how are these undergraduate students using propositional and non-propositional knowledge structures in these excerpts? First, they begin, like the $\mathrm{PhD}$ students, by stating the propositionally expressed principle that the total entropy of a system and its surroundings increase in processes involving temperature equalisation, i.e. the second law of thermodynamics. Their metaphorical use of 'drives' is embedded in this proposition in a conventional, textbook formulation of the second law. Then the students try to make sense of what is happening at the molecular level in order to provide a mechanistic explanation of the phenomenon (cf. Brown \& Clement, 1989). S1 uses the CMs Change Of State Is Transfer Of A Possession (applied to energy) and the metaphorical construal of energy as a resource. Again, these two metaphorical construals of energy are highly conventional metaphorical expressions that the students would have encountered in textbooks. Importantly, their use of metaphors is not productive here (that is, their use does not lead them to generate novel metaphorical expressions consistent with the underlying mapping as in 'if you take heat from 
the beaker and move to...' from the $\mathrm{PhD}$ students' problem solving described above). In addition, their use does not help them interpret the law that they state at the beginning or link it to the specific physical situation they are considering in the problem; yet another case of 'the Icarus effect' (Georgiou, 2014). Moreover, they are not able to retrieve the appropriate mathematical representation $(d S=d Q / T)$ that could help them develop their answer. In the absence of these, their problem solving gets stuck and they do not manage to connect the stated principle of entropy increase with the mechanism of heat transfer from the system to its surroundings. Instead, S2 ends up puzzled with the role of water freezing at a certain temperature.

Problem 3. We turn next to the undergraduates' dialogue regarding Problem 3. The central reasoning episode for this problem is presented in the following excerpt:

S1: But this is... here, you do not have any heat exchange with the surroundings... and since I did this quite recently, I remember that the entropy... I mean, the entropy change of an adiabatic process is zero... and here it is, because Q [the exchanged heat] is equal to zero.../.../

S2: ... or the entropy increase when the gas expands is counteracted by there being a temperature decrease... /... . ..well, temperature decrease is that every molecule gets less kinetic energy. /.../

$\mathrm{S} 1$ : When one pulls out... or it [the piston] is pushed out like this... and the molecules collide with the wall and exert pressure... they lose energy, because it is on its way outwards. /.../ so then, they have lower velocity when they fly back from the collisions. It may seem very strange! The volume increases enormously, but the entropy does not increase and it gets a lot colder.

Marked in bold are words used metaphorically reflecting the use of a number of CMs. The CM Change Of State Is Transfer Of Possession is applied to heat (reflected in 'heat exchange') and energy ('every molecule gets less kinetic energy' and 'they lose energy'). In addition, the metaphorical use of pronouns indicates two underlying CMs: A Problem Solver Is An Owner Of A System (reflected in 'you do not have any heat exchange') and A Problem Solver Is A Manipulator Of A System (reflected in 'when one pulls out [the piston]').

We now focus on, as with the previous episodes analysed, the roles of propositional and non-propositional knowledge structures. S1 recalls having encountered a similar situation/problem recently, and in line with the $\mathrm{PhD}$ students, she begins by stating the propositionally formulated principle that adiabatic processes do not involve heat exchange, which - in combination with the stated reversibility of the process - leads to a zero entropy change. It is reasonable to infer that this conclusion relies on the implicit assumption of the 
(propositional) mathematical formula $d S=d Q / T=0 \mathrm{~J} / \mathrm{K}$. These two propositions help the pair get straight to an answer of the entropy change, and this seems to constrain the reasoning that follows as they explain the underlying physical process. (Again, the hypothesis that these propositions play the role of constraint on reasoning comes from the discourse e.g. an authoritative statement with no hedging - 'the entropy change of an adiabatic process is zero' - and the subsequent reasoning assumes total entropy change is zero.)

The relatively few CMs are used in the following way. The CM Change Of State Is Transfer Of Possession (applied to heat) is a direct (conventional) metaphorical use based on knowing what adiabatic means, expressed in 'you do not have any heat exchange with the surroundings'. This supports the interpretation of the implicitly invoked formula $d S=d Q / T$. When providing their explanation of the process, the entropy change is construed as consisting of two components - associated with the increase in volume (which contributes positively to the entropy change) and the reduction in temperature (which contributes negatively to the entropy change). The use of 'counteracts' is a metaphorical construal of these two contributions as two opposing tendencies, interpreted in terms of force dynamics (Talmy, 1988). Similar to the PhD students, S1 finds the unchanged entropy 'strange', i.e. not in line with her immediate intuitions, and this tension between the result of their principlebased reasoning and intuition prompts them to search for a way to reconcile the ideas.

$\mathrm{S} 2$ introduces a microscopic perspective in connecting the temperature decrease to the average kinetic energy of the molecules of the gas. S1 adopts this molecular perspective in providing an explanatory model (Brown \& Clement, 1989), where she imagines what would happen 'when one pulls out' the piston, by using the CM A Problem Solver Is A Manipulator Of A System. The CMs Change Of State As Transfer Of Possession (applied to energy) and the States Are Possessions (applied to velocity) are also used in this explanation, which involves the imagistic simulation of the situation with conventional metaphorical interpretations of energy and velocity. However, as opposed to the $\mathrm{PhD}$ students' expression 'one walks along the same line' in relation to the same problem, in this imagistic reasoning, there is a clear distinction between the undergraduate students themselves as manipulators and the molecules as components of the system, referred to as 'they' in a detached way. Nonetheless, these undergraduates, with one of them having just encountered the problem before, manage to coordinate propositional principles at the macroscopic level with imagistic reasoning, and are able to make sense of the propositionally expressed principle at the microscopic level. 


\section{Contrasting PhD and Undergraduate Student Problem Solving}

We have now seen examples of how the $\mathrm{PhD}$ and undergraduate students approached the exercises, and how successful problem solving largely depended on a productive coordination of appropriate physics principles and non-propositional imagistic resources. The analysis shows that the $\mathrm{PhD}$ students are more likely to use conceptual metaphors to interpret aspects of propositional representations and to coordinate joint use of multiple propositional representations. Moreover, they are more likely to use conceptual metaphors to help apply propositional representations to specific problem situations. Partial success at problem solving on the part of the undergraduate students indicates some joint use of propositional and non-propositional representation. However, conceptual metaphors were minimally used to interpret aspects of propositional representations and relate propositions to the physical situation. Instead, they were used to develop a explanatory model, that might help make sense of the correctness of the proposition.

An additional dimension along which the $\mathrm{PhD}$ students differ from the undergraduates is the degree to which they engage or empathise with the studied phenomena (Ochs et al., 1996; Root-Bernstein, 2002). Even though both pairs engage with the modelled systems and manage to coordinate principles and intuitive resources in Problem 3, where the $\mathrm{PhD}$ students imagine how 'one walks along the same line' in a very visceral way, the undergraduate students are still rather confined to formulaic physics language, as in 'you do not have any heat exchange with the surroundings'. In fact, the detached language of the undergraduate students often comes across as similar to formal written science texts.

This difference in the reasoning and dialogue between the pairs is more a matter of degree than a clear dichotomy (which might reflect the closeness of the apprentice and journeyman categories in Hoffman's (1998) hierarchy of levels of expertise). Nevertheless, a quantitative pattern emerges from the way the two pairs used conceptual metaphors, reflecting their own role as problem solvers, in combination with personal pronouns. This is concluded from an analysis of the metaphorical use of pronouns in all dialogue turns of the problem-solving exercises of the two pairs (see Table 1), using a categorization scheme of three levels of engagement, inspired by Ochs, et al. (1996). At the lowest level of engagement, the problem solver conceives of observing or owning the considered system, but does not imagine interacting with it. At the next level, the problem solver envisions manipulating the system, and thinks through the consequences. Finally, at the highest level of engagement, the problem solver actually identifies with the system. 
[Table 1 about here]

Overall, the PhDs provided considerably more metaphorical construals of this type than the undergraduates (51 compared to 10, respectively), which cannot be explained solely by their larger number of turns overall (523 vs. 238). It may be noted that the most frequent category for the $\mathrm{PhD}$ students, as opposed to the undergraduates, was the lowest level of engagement, that of an observer or owner of the system. Nevertheless, some of these utterances, such as: "more than what I lose in the beaker" are far from typical formal science text, and could plausible have been coded as cases of identification with the system, rather than that of an owner of the system (but we conservatively decided on interpretations of less engagement when in doubt) In addition, only the PhD students arrived at the highest level of engagement, identification, as in: 'it's a question of that one walks along the same line'.

\section{Discussion}

Conceptual Metaphors and the Coordination of Propositional and Non-propositional Knowledge Structure in Problem Solving

The present study sought to contribute to the existing literature on development of expertise in scientific problem solving. Specifically, it intended to add to that body of literature that has identified the coordination of propositional and non-propositional knowledge structures by focusing on the role of conceptual metaphors in this coordination at two different levels of expertise: apprentices (undergraduate students) and journeymen ( $\mathrm{PhD}$ students). As summarised at the end of the last section, we found that journeymen invoked propositionally expressed principles and laws that were relevant for any given problem, which then served as constraints on their formulation and elaboration of a problem solution. Non-propositional knowledge structures in the form of the image-schematic source domains of conceptual metaphors and the conceptual schemas of symbolic forms were then invoked and coordinated to interpret these propositional structures. A particularly prominent aspect of the use of conceptual metaphors by the journeymen was the degree of engagement between the problem solvers, on the one hand, and the physical situation and quantitative reasoning, on the other. The use of conceptual metaphors transformed what might have been expected to be highly formal reasoning to a process of reasoning that contained many elaborate concrete, imagistic 
scenarios in which the problem solver him-/herself is construed as a component. In contrast, while often able to invoke the appropriate law or principle, the apprentices were either unable to coordinate, or were limited in coordinating, the needed imagistic elements that would support adequate interpretation of the propositions and laws, apply them to the physical situations or align qualitative and quantitative reasoning.

In light of the analyses presented here, we hypothesise that conceptual metaphors play a subtle role in the development of expertise in scientific problem solving. We suggest that they serve as flexible resources that allow the problem solver to construe abstract concepts in terms of a variety of more concrete schemata and serve to coordinate understanding of verbally formulated scientific principles, mathematically expressed laws and concrete images of the physical situations being reasoned about. As we have seen, diSessa and Sherin (1998) have described this kind of dynamic knowledge system in terms of a coordination class composed of multiple elements of different kinds: propositionally expressed beliefs, image schemas (e.g. p-prims) and mental models. The role of such a system is to support the ability to first "read out" (or "see") certain physical quantities in particular situations, and then to infer various other quantities and their magnitudes. Image schematic structures are seen as playing an important role for both reading out and inferring, with propositional structures playing a particularly important role in the latter. Thus, we suggest that conceptual metaphors are potentially important components of coordination classes. Future research is still needed to support this claim further and to clarify the nature of the role of conceptual metaphors as a component of coordination classes alongside other knowledge elements.

The present study also adds to previous work on the coordination of propositional and non-propositional knowledge structures (Cheng \& Brown, 2010; Georgiou, 2014; Singh, 2002) by pointing out the role of a knowledge type that has not been studied much to date - i.e. conceptual metaphors - and by being more explicit about the nature and role of a variety of knowledge elements involved in expert scientific problem solving. Moreover, as we have pointed out and discussed in previous work (Amin, 2009; Amin et al., 2012; Jeppsson et al., 2013), the use of concrete image-schematic source domains of conceptual metaphors in abstract, scientific problem solving shows that the role of ontological classification in the development of scientific expertise is not at all simple. In light of the present study, we can add that implicit concrete construals of abstract concepts such as entropy, energy and heat in terms of possessions, movement of possession, containment, etc. in the context of advanced scientific problem solving can be more prevalent at higher levels of expertise, and not necessarily a sign of naïve reasoning (Chi, Slotta, \& De 
Leeuw, 1994). This makes more complex the question of what ontological shifts occur with the development of expertise.

Indication of Coordination of Principles and Non-formal Resources in a Master's Formal Science Writing

In this study, we have focused our analysis on problem-solving dialogue, performed by apprentices and journeymen, at various points along their journey from novice to master. It may be worth investigating whether the identified patterns extend across other genres of scientific communication or along the novice-expert continuum. For this purpose, we have also looked at Einstein's (1905/1998) seminal paper where he introduced a quantum interpretation of the photoelectric effect, for which he was awarded the 1921 Nobel Prize in Physics. In Hoffman's (1998) classification along the novice-master continuum, Einstein is undoubtedly a master.

First, it should be noted that the entire paper is framed as an ontological discussion, in terms of what is the fundamental character of energy:

According to Maxwell's theory, energy is considered to be a continuous spatial function for all purely electromagnetic phenomena, hence also for light, whereas according to the present view of physicists, the energy of a ponderable body should be represented as a sum over the atoms and electrons (Einstein, 1905/1998, p. 177).

In contrast to Maxwell's view, in this paper Einstein suggests that energy is quantised, i.e. distributed discontinuously, also in relation to electromagnetic phenomena. In other words, from the perspective of Chi's line of work (e.g. Chi et al., 1981; Chi et al., 1994), this is a case where the master of masters is problematising the ontological categorisation of one of the central concepts in science. He challenges the physical principles that had been adopted up until that point - the fundamental premises of classical physics, and thereby opens up for the modern physics of the 1900s. In his account of the photoelectric effect, he says:

According to the view that the incident light consists of energy quanta of energy (R/N) $\beta v$, the production of cathode rays by light can be conceived in the following way. The body's surface layer is penetrated by energy quanta whose energy is converted at least partly into kinetic energy of the electrons. The simplest conception is that a light quantum transfers its entire energy to a single 
electron; we will assume that this can occur. However, we will not exclude the possibility that electrons absorb only a part of the energy of the light quanta (Einstein, 1905/1998, p. 194).

In the first sentence, Einstein restates the main claim of the paper: the physical principle that energy is quantised. Next, against this background, he invites us to imagine the process of production of cathode rays, a concrete physical phenomenon. In this way, he frames the ontological discussion within the particularities of an imagined situation, a case of coordination of formal and non-formal knowledge resources. In spite of this invitation to imaginative thought, in this excerpt, Einstein does not express personal engagement with the phenomenon, of the kind presented by Ochs et al. (1996) and adopted in the problem-solving dialogues of the current study. He does use non-propositional resources in the form of metaphor, however. Einstein describes how energy quanta 'penetrate' a body's surface layer, a process in which some or all of its energy is 'transferred to' and 'converted into' kinetic energy of the electrons. In our interpretation, the energy quanta or light quanta are construed as a kind of 'energy carrier' (Falk, Herrmann, \& Schmid, 1983), that collides with and delivers a certain amount of energy to the surface, while energy is treated as an object that moves from one location to another; a case of the use of an Object Event-Structure metaphor in relation to energy. In addition, in 'energy is converted /.../ into kinetic energy', different energy forms, such as kinetic energy are construed as locations, into which the energy transforms, a use of the CM Forms Of Energy Are Locations/Containers (Amin, 2009). Finally, when discussing whether all or only some of the energy of a light quantum is transferred to an individual electron, Einstein expresses that the electrons 'absorb' energy, a liquid-like version of the Object Event-Structure metaphor.

It may be worth noting, however, that whereas Einstein coordinates imagistic thought with the postulated physics principle of quantised energy, he uses considerably more detached language in relation to the concept of entropy throughout the paper. For instance, in relating Planck's quantum approach to come to terms with the problem of infinite energy density of black-body radiation, the so called ultraviolet catastrophe, Einstein (1905/1998, p. 186) says:

If we restrict ourselves to investigating the dependence of the entropy on the volume occupied by the radiation, and denote the entropy of the radiation by $S_{0}$ at volume $v_{0}$, we obtain $S-S_{0}=\frac{E}{\beta v} \ln \left[\frac{v}{v_{0}}\right]$. 
Here, in contrast to the visceral nature of energy as an embodied entity in the excerpts above, entropy is construed as a purely mathematical quantity, the value of which is 'obtained' from algebraic calculations.

In conclusion, even in this formal genre, the scientific paper, a master employs imagistic thought when querying into the fundamental nature of energy. However, the contrasting case of entropy shows that such coordination with imagistic thought is used selectively in relation to different concepts and contexts of explanation.

\section{Implications for Science Education Research and Practice}

The view of developing expertise in scientific problem solving that emerges from this study has a number of implications for science education. We focus our discussion here on the implications of the complexity of the coordination of knowledge elements required, the role of propositional knowledge structures as constraints on that coordination, and the implicit and subtle nature of the metaphorical construals involved.

The development of expertise in scientific problem solving seems to involve the complex coordination of various kinds of propositional and non-propositional knowledge structures. Moreover, the specifics of these coordinations are different in the context of different problem situations. An implication of these findings is in line with the general educational implications of a situated view of cognition (Greeno, 1989; Lave, 1988). The development of competence in an academic discipline relies on gaining experiences with authentic practices, and not merely a matter of exposure to abstract principles. As acknowledged by Hake $(1998$, p. 65) in relation to undergraduate mechanics courses, traditional approaches 'relying primarily on passive-student lectures, recipe labs, and algorithmic-problem exams' have not been found to support conceptual understanding among the participants in a sufficient way, but should be replaced by approaches characterised by 'interactive engagement'.

One possible approach for students to get exposed to authentic science practices is different kinds of internship or apprenticeship - in a more literal sense than in the scheme adopted by Chi (2006b) and as used up until now in this study. If students are invited to science laboratories, adopting the role of 'peripheral participants' (Lave, 1988), they get to experience how scientists apply abstract principles to concrete phenomena and problems through modelling of authentic discourse. Such direct involvement in science-laboratory 
activities typically begins towards the end of undergraduate programs, but might be considered much earlier.

Another approach to encourage interactive engagement and coordination of propositional and non-propositional resources is one that has been developed by Close and Scherr and colleagues (e.g. Scherr et al., 2013) within their Energy Courses. Here participants are introduced to physical phenomena of increasing complexity, and invited to make sense of the involved concepts and represent the phenomena in different ways in peergroup collaboration.

While much of the skill of scientific problem solving that we have described in this study is of an implicit, subtle nature, we have shown that invoking appropriate principles and laws and explicitly treating them as constraints on the process of problem solving was an important contributor to successful problem solving. This implies an important role for explicit instruction into scientific problem solving. Instructing learners into identifying suitable principles and laws and treating them as constraints, even when intuitions can suggest otherwise, is an important metacognitive stance to encourage. This is consistent with traditional instruction, but learners must also be given the opportunity to engage in a form of sense making that draws on non-propositional knowledge structures as well. This paper has suggested that we consider conceptual metaphors among those that might be relevant to expertise acquisition.

\section{Note}

(1) The interaction between these three conceptual domains could be analysed from the perspective of 'conceptual blending' (Fauconnier \& Turner, 1998). We have not adopted and applied this framework formally here, but see e.g. Close and Scherr, this issue, and Dreyfus, Gupta, and Redish, this issue, for examples of such analyses.

\section{References}

Amin, T. G. (2009). Conceptual metaphor meets conceptual change. Human Development, 52(3), 165-197. 
Amin, T. G., Jeppsson, F., Haglund, J., \& Strömdahl, H. (2012). The arrow of time: metaphorical construals of entropy and the second law of thermodynamics. Science Education, 96(5), 818-848.

Amin, T. G., Smith, C. L., \& Wiser, M. (2014). Student conceptions and conceptual change: Three overlapping phases of research. In N. G. Lederman \& S. K. Abell (Eds.), Handbook of research in science education (2nd ed., pp. 57-81). New York, NY: Routledge.

Andersson, B. (1986). The experiential gestalt of causation: a common core to pupils' preconceptions in science. European Journal of Science Education, 8(2), 155-171.

Barsalou, L. (2008). Grounded cognition. Annual Review of Psychology, 59(1), 617-645.

Brookes, D. T., \& Etkina, E. (2007). Using conceptual metaphor and functional grammar to explore how language used in physics affects student learning. Physical Review Special Topics - Physics Education Research, 3(1), 010105.

Brookes, D. T., \& Etkina, E. (2009). "Force," ontology, and language. Physical Review Special Topics - Physics Education Research, 5(1), 010110.

Brosseau, C., \& Viard, J. (1992). Quelques réflexions sur le concept d'entropie issues d'un enseignement de thermodynamique [Some reflections on the entropy concept from thermodynamics teaching]. Enseñanza de las ciencias, 10(1), 13-16.

Brown, D. E., \& Clement, J. (1989). Overcoming misconceptions via analogical reasoning: abstract transfer versus explanatory model construction. Instructional Science, 18(4), 237-261.

Cheng, M. F., \& Brown, D. E. (2010). Conceptual resources in self-developed explanatory models: The importance of integrating conscious and intuitive knowledge. International Journal of Science Education, 32(17), 2367-2392.

Chi, M. T. H. (2006a). Laboratory methods for assessing experts' and novices' knowledge. In A. Ericsson, N. Charness, P. J. Feltovich, \& R. Hoffman (Eds.), The Cambridge handbook of expertise and expert performance (pp. 167-184). New York, NY: Cambridge University Press.

Chi, M. T. H. (2006b). Two approaches to the study of experts' characteristics. In A. Ericsson, N. Charness, P. J. Feltovich, \& R. Hoffman (Eds.), The Cambridge handbook of expertise and expert performance (pp. 21-30). New York, NY: Cambridge University Press.

Chi, M. T. H., Feltovich, P. J., \& Glaser, R. (1981). Categorization and representation of physics problems by experts and novices. Cognitive Science, 5(2), 121-152. 
Chi, M. T. H., Glaser, R., \& Rees, E. (1982). Expertise in problem solving. In R. J. Sternberg (Ed.), Advances in the psychology of human intelligence (Vol. 1, pp. 7-75). Hillsdale, NJ: Erlbaum.

Chi, M. T. H., Slotta, J. D., \& De Leeuw, N. (1994). From things to processes: A theory of conceptual change for learning science concepts. Learning and Instruction, 4(1), 2743.

Clark, A. (2008). Supersizing the mind: embodiment, action, and cognitive extension. Oxford, UK: Oxford University Press.

Clement, J. (2009). Creative model construction in scientists and students: the role of imagery, analogy, and mental simulation. Dordrecht, NL: Springer.

diSessa, A. A. (1993). Toward an epistemology of physics. Cognition and Instruction, 10(23), 105-225.

diSessa, A. A., \& Sherin, B. L. (1998). What changes in conceptual change? International Journal of Science Education, 20(10), 1155-1191.

Dreyfus, H. L., Dreyfus, S. E., \& Athanasiou, T. (1986). Mind over machine: the power of human intuition and expertise in the era of the computer. New York, NY: Free Press.

Einstein, A. (1905/1998). On a heuristic point of view concerning the production and transformation of light. In J. Stachel (Ed.), Einstein's miraculous year: Five papers that changed the world of physics (pp. 177-198). Princeton, NJ: Princeton University Press.

Einstein, A. (1954). Ideas and opinions. New York, NY: Crown.

Falk, G., Herrmann, F., \& Schmid, G. B. (1983). Energy forms or energy carriers? American Journal of Physics, 51(12), 1074-1077.

Fauconnier, G., \& Turner, M. (1998). Conceptual integration networks. Cognitive Science, 22(2), 133-187.

Georgiou, H. (2014). Doing positive work: On student understanding of thermodynamics. ( $\mathrm{PhD}$ dissertation), The University of Sydney, Sydney, Australia.

Greeno, J. G. (1989). A perspective on thinking. American Psychologist, 44(2), 134-141.

Haglund, J., \& Jeppsson, F. (2014). Confronting conceptual challenges in thermodynamics by use of self-generated analogies. Science \& Education, 23(7), 1505-1529.

Hake, R. R. (1998). Interactive-engagement versus traditional methods: A six-thousandstudent survey of mechanics test data for introductory physics courses. American Journal of Physics, 66(1), 64-74. 
Hammer, D. (2000). Student resources for learning introductory physics. American Journal of Physics, 68(S1), S52-S59.

Hoffman, R. R. (1998). How can expertise be defined? Implications of research from cognitive psychology. In R. Williams, W. Faulkner, \& J. Fleck (Eds.), Exploring expertise (pp. 81-100). Mahwah, NJ: Erlbaum.

Jeppsson, F., Haglund, J., Amin, T. G., \& Strömdahl, H. (2013). Exploring the use of conceptual metaphors in solving problems on entropy. Journal of the Learning Sciences, 22(1), 70-120.

Johnson, M. (1987). The body in the mind: the bodily basis of meaning, imagination, and reason. Chicago, IL: University of Chicago Press.

Lakoff, G., \& Johnson, M. (1980). Metaphors we live by. Chicago, IL: The University of Chicago Press.

Lakoff, G., \& Johnson, M. (1999). Philosophy in the flesh. New York, NY: Basic Books.

Lakoff, G., \& Núñez, R. E. (2000). Where mathematics comes from: How the embodied mind brings mathematics into being. New York, NY: Basic Books.

Larkin, J., McDermott, J., Simon, D. P., \& Simon, H. A. (1980). Expert and novice performance in solving physics problems. Science, 208(4450), 1335-1342.

Lave, J. (1988). Cognition in practice: mind, mathematics and culture in everyday life. Cambridge, UK: Cambridge University Press.

Ochs, E., Gonzales, P., \& Jacoby, S. (1996). "When I come down I'm in the domain state": grammar and graphic representation in the interpretive activity of physicists. In E. Ochs, E. A. Schegloff, \& S. A. Thompson (Eds.), Interaction and grammar (pp. 328369). Cambridge, UK: Cambridge University Press.

Pragglejaz_Group. (2007). MIP: A method for identifying metaphorically used words in discourse. Metaphor and Symbol, 22(1), 1-39.

Reiner, M. (2000). Thought experiments and embodied cognition. In J. K. Gilbert \& C. J. Boulter (Eds.), Developing models in science education (pp. 157-176). Dordrecht, the Netherlands: Kluwer.

Reiner, M., \& Gilbert, J. (2000). Epistemological resources for thought experimentation in science learning. International Journal of Science Education, 22(5), 489-506.

Root-Bernstein, R. S. (2002). Aesthetic cognition. International Studies in the Philosophy of Science, 16(1), 61-77.

Salk, J. (1983). The anatomy of reality. New York, NY: Columbia University Press. 
Scherr, R. E., Close, H. G., Close, E. W., Flood, V. J., McKagan, S. B., Robertson, A. D., . . . Vokos, S. (2013). Negotiating energy dynamics through embodied action in a materially structured environment. Physical Review Special Topics - Physics Education Research, 9(2), 020105.

Sherin, B. L. (2001). How students understand physics equations. Cognition and Instruction, 19(4), 479-541.

Sherin, B. L. (2006). Common sense clarified: The role of intuitive knowledge in physics problem solving. Journal of Research in Science Teaching, 43(6), 535-555.

Singh, C. (2002). When physical intuition fails. American Journal of Physics, 70(11), 11031109.

Slotta, J. D., Chi, M. T. H., \& Joram, E. (1995). Assessing students' misclassifications of physics concepts: An ontological basis for conceptual change. Cognition and Instruction, 13(3), 373-400.

Smith, J. P., diSessa, A. A., \& Roschelle, J. (1993). Misconceptions reconceived: A constructivist analysis of knowledge in transition. Journal of the Learning Sciences, $3(2), 115-163$.

Stolpe, K., \& Björklund, L. (2011). Seeing the wood for the trees: Applying the dual-memory system model to investigate expert teachers' observational skills in natural ecological learning environments. International Journal of Science Education, 34(1), 101-125.

Talmy, L. (1988). Force dynamics in language and cognition. Cognitive Science, 12(1), 49100.

Varela, F. J., Thompson, E., \& Rosch, E. (1991). The embodied mind: cognitive science and human experience. Cambridge, MA: MIT Press.

Wilensky, U., \& Reisman, K. (2006). Thinking like a wolf, a sheep, or a firefly: Learning biology through constructing and testing computational theories-An embodied modeling approach. Cognition and Instruction, 24(2), 171-209. 


\begin{tabular}{lccc}
\hline Conceptual metaphors & $\begin{array}{c}\text { Under- } \\
\text { graduates }\end{array}$ & PhDs & Example utterance \\
\hline $\begin{array}{l}\text { A Problem Solver Is An } \\
\text { Owner/ Observer Of A }\end{array}$ & 1 & 30 & 'more than what I lose in the beaker' \\
$\begin{array}{l}\text { System } \\
\text { A Problem Solver Is A } \\
\begin{array}{l}\text { Manipulator Of A System } \\
\text { A Problem Solver Is A }\end{array}\end{array}$ & 9 & 17 & 'Phen one pulls out [the piston]' \\
System & 0 & 4 & 'one walks along the same line' (PhDs) \\
\hline
\end{tabular}

Table 1. Frequencies of pronouns ('I', 'you', 'we', or 'one') used as constituents in conceptual metaphors, which reflect different levels of engagement with the phenomena considered in the problem-solving dialogues 